\title{
Successful Business Model Types of Cloud Providers
}

\author{
Stine Labes $\cdot$ Nicolai Hanner $\cdot$ Ruediger Zarnekow
}

Received: 28 May 2015/Accepted: 2 May 2016/Published online: 9 November 2016

(C) Springer Fachmedien Wiesbaden 2016

\begin{abstract}
The acceleration of technical change in the fast moving electronics market increases the uncertainty and risk for IT providers. Influenced by new IT provisioning concepts such as cloud computing, providers are looking to identify stable guidelines and success factors within existing and new business models. The authors have conducted an intensive analysis of the business model characteristics of 45 providers in the cloud market that are critical to success. A cloud business model framework with 105 characteristics was used to systemize the business models, and the data was analyzed statistically in regard to indicators for success. The results revealed 42 success-related business model characteristics, and a cluster analysis led to three common combinations of characteristics that describe meta types of cloud business models. The most promising meta type is a specialized cloud provider with customer-oriented branch solutions, while small-scale newcomers with aggregation services experience difficulties to be competitive. To evaluate and verify the results and the success of each business model type, 12 expert interviews were conducted. The interview statements were aggregated and summarized to offer recommendations for action and a prediction for the success of cloud business models.
\end{abstract}

Accepted after two revisions by Prof. Dr. Bichler.

Dr. S. Labes $(\square) \cdot$ N. Hanner · Prof. Dr. R. Zarnekow

Technische Universität Berlin, Straße des 17. Juni 135,

10623 Berlin, Germany

e-mail: Stine.labes@tu-berlin.de

N. Hanner

e-mail: Nicolai.hanner@tu-berlin.de

Prof. Dr. R. Zarnekow

e-mail: Ruediger.zarnekow@tu-berlin.de
Keywords Cloud computing · Business model · Success factors - Qualitative content analysis - Expert interviews . Cloud provider · Value proposition - Cloud strategy

\section{Introduction}

Since the new digital economy (Cohen et al. 2000; Gordon 2000) emerged in the late 1990s, the business model concept has become more significant, not only in practice but also in academic research (Veit et al. 2014). The drivers of this development are firstly the improved performance of information and communication technologies (ICT) (Cohen et al. 2000; Gordon 2000), especially in regard to data processing and data transmission (Staehler 2002). Secondly, the internet functions as an enabler for interactivity, ubiquity, multimediality and distribution, and penetrates the economy and society faster than other mass media types (Cohen et al. 2000; Zerdick et al. 2001). With the acceleration of technical changes in ICT and the diffusion of ICT products, uncertainty and risk has grown with the development of new business models. Forecasts or longterm technology plans are limited, thus investments are fraught with higher risk (Bettis and Hitt 1995).

One example of these fast developing business models is cloud computing (Gartner 2013). With this business concept, cloud providers offer freely scalable IT resources (e.g., servers, storage, applications, or network resources) in an on-demand manner via networks, and receive usage-based revenue streams in return (Mell and Grance 2011; Hayes 2008; Weinhardt et al. 2009). The cloud market is highly diverse because the standardized and hierarchically structured services are able to build on one another. Different provisioning models (e.g., public, private, hybrid, and community) increase this 
complexity, and thus there is a need for stable guidelines which offer a reliable prediction of success. In this context, our comprehension of success primarily addresses the ability of a provider to gain market visibility and to generate profits.

The business model concept may be seen as an analysis unit that takes new conditions into account (Staehler 2002). The objective of a business model is to set a foundation for understanding the appreciation of an existing business, to recognize one's own weaknesses in achieving business improvement, and also to systematically evaluate new business ideas with regard to their competitive advantages and success probabilities (Staehler 2002). When describing a business model, most approaches use a component-based consideration of "what a company is doing in order to create and commercialize value" (Burkhart et al. 2011) (see also Osterwalder et al. 2010; Wirtz 2010). Although a high number of researchers have analyzed this concept, until now a common business model definition has been missing (Zott et al. 2011; Lambert and Davidson 2013). We analyzed the classifications offered in previous research (Shafer et al. 2005; Al-Debei and Avison 2010; Burkhart et al. 2011; Zolnowski and Boehmann 2011; Zott et al. 2011) and came up with 30 definitions. These were aggregated into eight components as a basis for our analysis (Labes et al. 2013b). The value creation side consists of the partner network, resources and activities, and costs. The cloud strategy and value proposition lie at the center, and target markets, distribution and customer relationship, and revenue streams belong to the side of value delivery. We then developed a detailed business model framework with 105 business model features drawn from these areas (Labes et al. 2013a). Within our present research, we have used this framework as an analysis unit for the examination of firstly the success-related factors of cloud provision businesses, and secondly their common business model types.

We have attempted to address the following research questions:

1. Which business model characteristics are related to the success of cloud business models and what is the most promising cloud provider type?

2. What can cloud providers do to increase their success?

To answer these questions we analyzed success factors for theoretical business models, and also conducted a comprehensive practical study of 45 cloud firms to determine their success-related characteristics and establish promising patterns. We discussed the results with cloud service providers, and conclude this article by providing of recommendations for the development of a cloud business and the associated prediction of success.

\section{Related Work}

Success factors are defined as "the limited number of areas in which results, if they are satisfactory, will ensure successful competitive performance for the organization" (Rockart 1979). Research on success factors goes back to the 1960s, but distinct research on successful business models is rare. An important work that focuses on success factors in general is the PIMS (Profit Impact of Marketing Strategies) study. In this study, Schoeffler et al. (1974) analyzed business data from 3000 business units and derived seven strategic factors that drive success. In 1979, Rockart mentioned critical success factors for businesses for the first time (Rockart 1979), and went on to conduct interviews with CEOs to detect reliable factors for their corporate success (Rockart 1982). Peters and Waterman (1982) analyzed 43 of Fortune 500's top performing companies and derived eight aspects essential for successful firms. Leidecker and Bruno (1984) proposed three levels of critical success factor analysis, using eight identification techniques. These were applied to reveal success factors for specific industries as well as for different companies. de Brentani (1991) analyzed generic success factors for new business services, and this can be applied to the cloud services we observe today.

Besides research into general success factors, some authors specifically focus on the provision of cloud computing. Horsti et al. (2004) conducted case study research and differentiated critical success factors and customer need factors for different maturity stages of an electronic business. With a special focus on the success factors of cloud-based software-as-a-service (SaaS) business, Ernst and Rothlauf (2012) revealed seven critical success factors from a literature-based argumentative study. Walther et al. (2012) also conducted literature-based research and derived 12 success factors for a SaaS type business.

We integrated the success factors identified in this previous research with the business model components described earlier and found many overlaps between success factors in both general and cloud specific literature (Table 1). This supports the assumption that some generic success factors are valid for cloud businesses, but still need specific supplementation. The results from the literature highlight the business strategy, the value proposition itself, and the resources and activities needed to create the value proposition.

\section{Research Approach}

Within our explorative research, we used a positivist approach (Myers 1997) to increase the understanding and prediction of business success. Osterwalder (2004) created 
Table 1 Critical success factors as reported in the literature

\begin{tabular}{|c|c|c|c|c|c|c|c|c|c|}
\hline \multirow[t]{2}{*}{ No. } & \multirow{2}{*}{$\begin{array}{l}\text { Critical success factors in business model } \\
\text { components }\end{array}$} & \multicolumn{8}{|c|}{ Generic focus $\rightarrow$ specific focus } \\
\hline & & $\begin{array}{l}\text { Schoeffler } \\
\text { et al. } \\
(1974)\end{array}$ & $\begin{array}{l}\text { Rockart } \\
(1982)\end{array}$ & $\begin{array}{l}\text { Peters and } \\
\text { Waterman } \\
\text { (1982) }\end{array}$ & $\begin{array}{l}\text { Leidecker } \\
\text { and Bruno } \\
\text { (1984) }\end{array}$ & $\begin{array}{l}\text { de } \\
\text { Brentani } \\
(1991)\end{array}$ & $\begin{array}{l}\text { Horsti } \\
\text { et al. } \\
\text { (2004) }\end{array}$ & $\begin{array}{l}\text { Ernst and } \\
\text { Rothlauf } \\
(2012)\end{array}$ & $\begin{array}{l}\text { Walther } \\
\text { et al. } \\
\text { (2012) }\end{array}$ \\
\hline 1 & $\begin{array}{l}\text { Business strategy, e.g., innovation, } \\
\text { differentiation, vertical integration } \\
\text { (universal or lean), flexible governance }\end{array}$ & $x$ & $x$ & $x$ & $x$ & $x$ & $x$ & $\times$ & $\times$ \\
\hline 2 & $\begin{array}{l}\text { Partner Network, e.g., pronounced partner } \\
\text { relationships }\end{array}$ & & & & $x$ & & $x$ & $\times$ & \\
\hline 3 & $\begin{array}{l}\text { Resources and activities, e.g., } \\
\text { productivity, know-how, reliable } \\
\text { infrastructure, active decision making, } \\
\text { management commitment }\end{array}$ & $x$ & $x$ & $x$ & $x$ & $x$ & $x$ & $x$ & $x$ \\
\hline 4 & $\begin{array}{l}\text { Costs, e.g., cost savings, synergies, } \\
\text { investment intensity, capital availability }\end{array}$ & $x$ & & & $x$ & $x$ & & $\times$ & $\times$ \\
\hline 5 & $\begin{array}{l}\text { Value Proposition, e.g., product portfolio, } \\
\text {-quality, security, flexibility, reversion, } \\
\text { interoperability, privacy, data control }\end{array}$ & $x$ & $x$ & & $x$ & $x$ & $\times$ & $\times$ & $\times$ \\
\hline 6 & $\begin{array}{l}\text { Distribution and customer relationship, } \\
\text { e.g., customer interaction, -care, } \\
\text { communication, image, SLA }\end{array}$ & & $\times$ & $x$ & $x$ & $x$ & $x$ & $x$ & \\
\hline 7 & Revenue, e.g., charging, price & & & & $\times$ & & & & $\times$ \\
\hline 8 & $\begin{array}{l}\text { Target Market, e.g., market position, - } \\
\text { attractiveness, -growth, -competitiveness, } \\
\text { segment adjustment }\end{array}$ & $x$ & & & & $x$ & & & \\
\hline
\end{tabular}

a business model ontology that helps to structure a business model, but it "is not a guarantee for success as it has to be implemented and managed". We took up this idea and conducted an intensive study of 45 cloud providers and their business models to determine aspects that may be related to a successful business model.

To develop a deeper understanding of the field, we mixed quantitative and qualitative methods (Venkatesh et al. 2013). Within this approach, we followed an explanatory method design (Creswell and Clark 2007) and combined a quantitative cross-sectional analysis of secondary data (see Sect. 4) with qualitative structured interviews to evaluate the results (see Sect. 5).

For the cross-sectional study, we systematically selected 45 cloud business models of relevant cloud providers or the cloud divisions of businesses with a wider product portfolio (for details, see Labes et al. 2015). To acquire the data, we comprehensively reviewed the companies' websites, encyclopedia items, blogs, and news feeds for empirical data. Two researchers reviewed the information in three cycles from January to July 2014. To evaluate the results, we used qualitative content analysis (Mayring 2004; Miles and Huberman 1994). Content analysis proposes three steps of data reduction, data display and drawing conclusions (Faust 1982; Hsieh and Shannon 2005; Miles and Huberman 1994).
For data reduction we coded the data using a systemized approach employed in previous research (Hsieh and Shannon 2005). This approach took the form of a detailed cloud business model framework (Labes et al. 2013a) with 105 business model characteristics (BMCs). These are classified in a morphological box that is aligned with the basic components of a business model. The BMCs show the possible design features required to "assemble" a business model, and they are potentially success-related (Osterwalder 2004). The coding process rated the BMCs in each business model $(0=$ "not represented", $1=$ "represented", 2 = "strongly represented"). The assessments were discussed and reviewed within the research team to verify the coding consistency (Thomas 2006).

For the data display, we summarized the data gathered from the 45 business models in a table aligned with the 105 $\mathrm{BMCs}$ to produce one database for statistical analysis. A correlation analysis identified critical BMCs regarding the indicators for success, and a cluster analysis revealed frequent combinations of BMCs that describe common business model types. Both analyses are independent from each other and the details are described in Sect. 4.

When drawing conclusions, we combined the analyses to discuss the success of the business model types.

In order to enrich the quantitative analysis results with a qualitative perspective based on primary data, we 


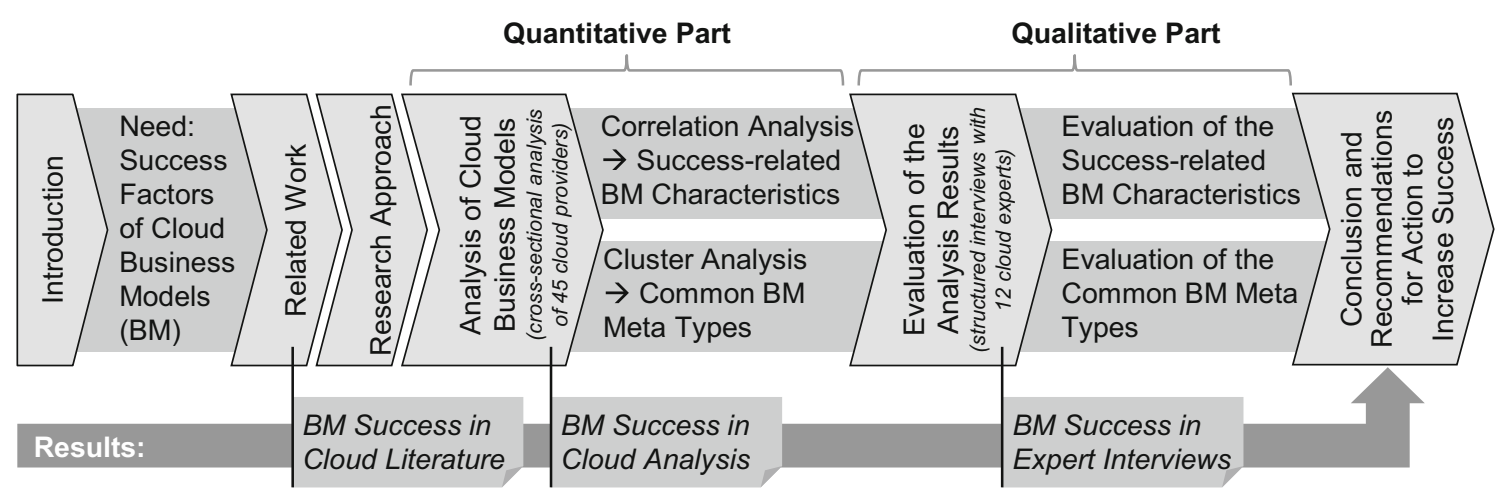

Fig. 1 Research approach for successful cloud business models

evaluated the analysis results during interviews with cloud experts. This approach is proposed in literature as being helpful to interpret and assess a specific issue (Gläser and Laudel 2010; Myers 1997). A structured procedure was employed to help identify the research issue, select the interview subjects, and to determine how the interviews would be conducted (Kirsch 2004). We selected 12 international experts on cloud computing that represent key stakeholder groups regarding the success of the cloud provider's business model. In our selection, we attached importance to obtaining a representative number of interview partners from different perspectives $(4 \times$ IT/cloud provider, $3 \times \mathrm{IT} /$ cloud customer, $3 \times \mathrm{IT} /$ cloud consultant, and $2 \times$ cloud broker). All of the experts had between 10 and 35 years' experience in IT and cloud computing, and held leading positions within their companies $(4 \times$ managing director, $2 \times$ IT manager, $2 \times$ IT consultant, $1 \times$ IT director, $1 \times$ operations director, $1 \times$ IT analyst, $1 \times$ business development manager). When conducting the interviews, we addressed specific interview criteria such as credibility, transferability, dependability, and conformability to enhance rigor and derive trustworthy results (Baxter and Eyles 1997). To this aim, a structured interview guide with 13 questions was developed that evaluated success factors for business models, and also the specific success of cloud provider types.

The interview guide was sent by mail to allow the experts to prepare well-reflected answers. Individual interviews were conducted either face-to-face or via telephone (Gaskell 2000) by the authors who have expert knowledge in the research area (Hopf 2004). Interviews lasted between 30 and $60 \mathrm{~min}$. To establish a natural and unbiased conversational situation, we decided not to use audio recording for the interviews (Gläser and Laudel 2010). The renouncement of recording and transcription can be tolerated in research (Liebhold and Trinczek 2009), especially if it is not important how the content is presented (Gläser and Laudel 2010), and if such recordings do not contribute significantly to the quality of the results (Franz and Kopp 2004). However, we documented each relevant piece of the expert's information on the developed interview protocol, including exact quotations where relevant. To evaluate the interviews, we again used a 3-step qualitative content analysis. For data reduction, the interview protocols were aggregated to offer a summary (Patton 2005; Schilling 2006). The information was then structured along the cloud provider types derived from the research findings of the statistical analyses to display the data. In the third step, we drew conclusions and compared the results of the qualitative interviews with the results of the statistical literature analyses. Finally, we summarized the discussion and derived recommendations for action regarding successful business models in the context of cloud market provision (Fig. 1).

\section{Analysis of Cloud Business Models}

\subsection{Critical Business Model Characteristics}

In determining the success factors of business models, we used the key indicator system, proposed by Rockart (1979) as offering the "best" approach (Rockart 1979). State of the art research suggests return on investment (ROI) as a common indicator for successful business models (e.g., Schoeffler et al. 1974). Due to the limited accessibility of financial data for cloud businesses, we calculated the EBIT margin (ratio of earnings per sales volume before interest and taxes) for cloud firms or in the case of larger companies for their cloud business area. Compared to absolute revenue and EBIT, the EBIT margin provides comparable information about the company's profitability, without any preference towards large companies. However, financial data are not the only and best indicator for business performance (Eccles 1991; Lee et al. 2008) and measures based on multiple indicators allow other influencing factors to be considered (Ittner et al. 2003; Grupp and Schubert 2010). Hence, we used a second indicator as researchers 
Table 2 Critical success-related business model characteristics in the analysis

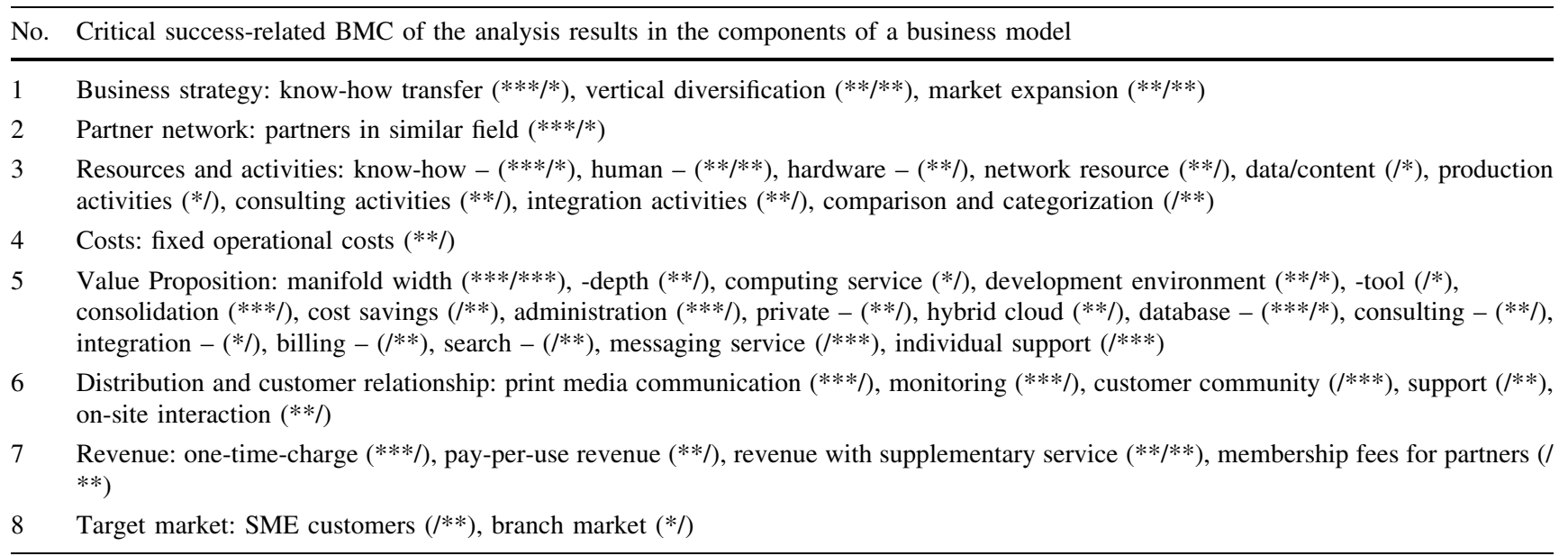
Spearman's rank correlation (EBIT margin/inlink count) $* \mathrm{p}<0.05, * * \mathrm{p}<0.025, * * * \mathrm{p}<0.01$, two-tailed test

state that there is a relation between the firm's web visibility and its business performance (Wang and Vaughan 2014; Vaughan 2004). As Wang and Vaughan (2014) revealed, there can be a significant correlation between the number of inbound links (web visibility) to a company's website and business performance. We argue that this is an especially suitable indicator for internet driven businesses such as cloud computing. To measure the inlink count, we used alexa.com as web data base, following the approach of Vaughan and Yang (2012).

To evaluate the robustness of the indicators, we calculated the Pearson correlation for interval scale between the indicators and analyzed whether the indicators treat the cloud providers equally and independently from a firms' size or age. Both indicators had no significant correlation ( $p$ value $>0.05$ ) with each other (correlation coefficient $=0.120)$ and are therefore seen as independent measures. The inlink count showed no significant correlation to the age $(-0.019)$, size of a firm $(0.052)$, or its revenue (0.257) and thus seemed to be a stable indicator. The EBIT margin also showed no significant correlation to the firms' age $(0.282)$, size $(0.262)$ or revenue $(0.287)$.

Using a correlation analysis between the data base and the two indicators, we identified characteristics that have a significant positive correlation to at least one indicator and correlate positively with the other. As a result, 42 characteristics emerged as critical for the success of the business models. We arranged the critical BMCs alongside the basic components of a business model (Table 2).

The critical BMCs highly emphasize the market experience and existing know-how from former business that was vertically expanded towards cloud computing. Furthermore, a manifold and wide cloud product portfolio that can consolidate the customer's IT landscape is related to success. A cloud platform including an application development environment and tools, monitoring, administration and individual support is critical to success, as is the option for customers to exchange experiences in different communities. Also related to the indicators for success are revenue streams from supplementary services. These success-related BMCs of a cloud business model are however only indications, and do not allow a reverse conclusion that $\mathrm{BMCs}$ that are not related to success are irrelevant for a successful business model.

Some expected features show no significant correlation because they are basic but essential features that each cloud firm must establish. This refers to characteristics that have a high adoption rate in the business models, but show no correlation. For example, 'Web interface' and 'Internet connection' are not revealed as success-related but are represented very strongly (average rating $>1.9$, "strongly represented") with a low variance within $100 \%$ of the business models. In addition, the BMCs 'Security', 'Scalability', and 'Support' are implemented by each firm (100\%) with a low variance and rated well above average (the average rating of all critical BMCs is 0.721 ), but they do not correlate significantly or even negatively. Although these BMCs are obviously relevant for a cloud business model, they cannot serve as unique differentiating characteristic for success.

Some other characteristics that strongly correlate with the indicators describe rather traditional aspects (e.g., 'Print media', 'On-site interaction' and 'One-time charge'). It can be assumed that traditional methods strengthen the trust in new and unstable environments like the cloud market and therefore correlate with success.

To provide a cross-check, we conducted a second analysis. Based on our results we quantified the number of 


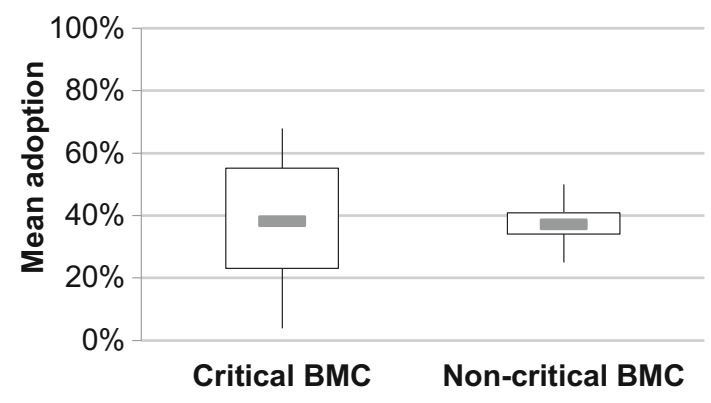

Fig. 2 Mean adoption of the critical business model characteristics

implemented critical BMCs in our sample and called this metric the 'mean adoption of critical BMCs'. We see evidence that the diversity between business models regarding critical $\mathrm{BMCs}$ is more significant than between the noncritical BMCs (Fig. 2, left). As the figure shows, the mean adoption of both critical and non-critical BMCs is about the same. Yet the adoption of critical BMCs is distributed with a high dispersion, whereas the non-critical BMCs do not differ much in our sample. This indicates that the implementation of critical BMCs has a stronger influence on the firm's success, while the implementation of non-critical BMCs has only marginal effects.

As to the analysis of firms regarding their relative mean adoption of critical BMCs, we can see that those with a larger EBIT margin and a better web visibility have an increased relative adoption of critical BMCs within their business models (Fig. 2, right). The ten leading companies are Media Temple, Century Link/Savvis, Dimension Data, Oracle, AT\&T, Microsoft, IBM, RedHat, EMC, and Cisco.

\subsection{Common Business Model Types}

We performed a cluster analysis on the database to discover general patterns in the BMCs. Cluster analysis is a method that determines unknown correlations in a data pool and helps to group similar data into clusters. In the ideal case, the clusters are internally homogeneous and externally heterogeneous (Anderberg 1973). The grouping can be based on similarity or distance measures, and for the

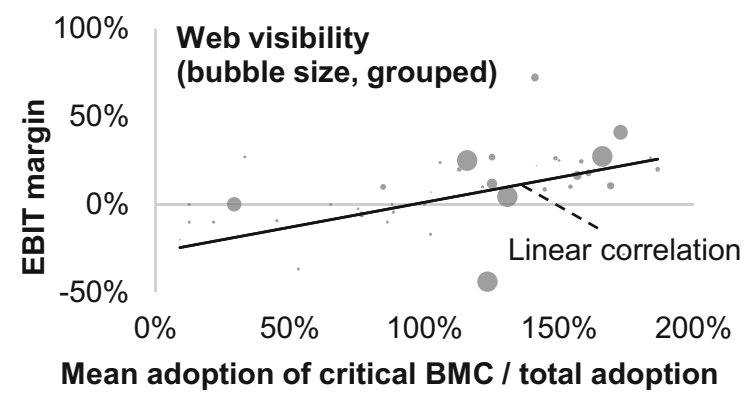

ordinal scale level used $(0=$ "not represented", $1=$ "represented", 2 = "strongly represented"), a similarity measure is more suitable (Bacher et al. 2010). To find an optimum of clusters, we chose an agglomerative hierarchical clustering method. This method starts with one aspect of data in one cluster and groups the clusters step by step according to their similarity until they belong to one route cluster. Due to high accuracy values we chose the agglomerative hierarchical clustering analysis with a squared Euclidean distance scale and minimum variance (Ward's method) (Blashfield 1976; Punj and Stewart 1983).

The cluster analysis mutually exclusively assigned the BMCs to three clusters (Fig. 3, left). The resulting BMCs for each cluster characterize this cluster the best, so that the implemented BMCs can be found primarily within this cluster but not necessarily exclusively. The clusters do not describe success-critical, but rather typical BMC combinations, thus we can interpret them as common meta types in business models. The types are characterized by a wellbalanced number of BMCs: cluster 1 with 38 BMCs (36\%), cluster 2 with 39 BMCs (37\%), and cluster 3 with 28 BMCs (27\%) (Fig. 3, middle). The implementations of the meta types in the analyzed business models vary in their average expression and their dispersion (Fig. 3, right). While the first type includes BMCs that have a low applicability in the featured business models (average implementation 14\%), BMCs of type 2 were applied relatively often (average implementation 65\%). Type 3 shows
Dissimilarity between clusters

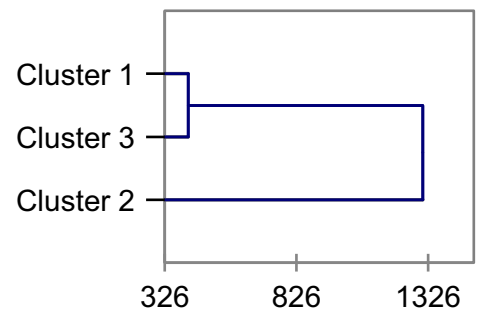

Number of BMC in the clusters

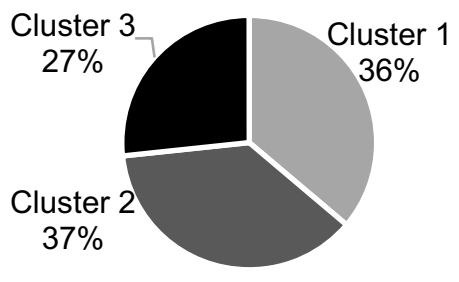

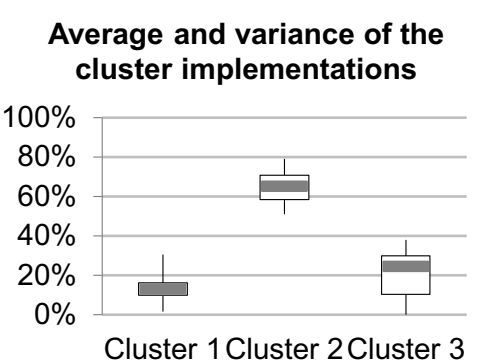

Fig. 3 Clusters of business model characteristics 


\section{Value creation}

Type 1: Newcomers with aggregation services possibly cooperating with partner revenue models

$\begin{gathered}\text { Human resource, } \\ \text { data \& content }\end{gathered}$
Type 2: Experienced player with standardized public cloud services and customer care for the mass market
$\begin{gathered}\text { Knowhow resource, } \\ \text { hardware resource }\end{gathered}$
Type 3: Specified providers with hybrid branch solutions and integration support at a high trust level
database \& search services

Fig. 4 Successful business model types

the highest variance in implementation, which implies that the component BMCs have a higher influence on success.

The first type describes newcomers that adapt existing cloud strategies or cooperate with substitutive partners within a community cloud in inter-organizational fields. The value proposition describes a limited service portfolio in depth and width, and allows for individual customization. The service creation is based on the activities of comparison and categorization that deliver structured data and content including database and search services, or it describes aggregation and add-on services such as billing services. These cloud services induce mainly initial costs. The target customers are located in niche markets and their communication mainly takes place via traditional channels such as print media or personal contacts. After a one-time charge, the revenue is made with supplementary services or via a partner revenue model.

The second type describes cloud providers that design and form the cloud market with a transfer of existing know-how. They primarily provide a variety of software services and aid with individual support and consulting assistance. The services are highly standardized, and offered as multi-tenancy public cloud service on a high security level. This allows high flexibility and scalability, as well as time and cost savings. The partner network is well established in complementary fields with technology and business partners. The cloud services are produced with proprietary hardware, software and know-how resources, which results in fixed and variable operational costs. The services address both the mass market and the individual firms. Well-developed support systems, as well as online profiles and communities serve to establish sound customer relationships. Revenue streams are based on subscriptions of the main service.

The third type describes providers that offer infrastructure and platform services with additional data processing, administration and marketplace services. They diversify their business on a vertical level to provide services with a manifold depth. The deployment models are both private and hybrid and enable a consolidated and sustainable IT environment for customers. Integration services help to migrate or connect legacy systems with the cloud environment. Consulting partners in similar fields support their own activities of consulting, integration, and on-site interaction at the customer's workplace. Target customers are specifically addressed in branch-specific and public sectors. A transparent monitoring of services as well as transparent SLAs help build a trustful customer relationship and enable a usage-based customer payment tariff.

To assess the cloud business model types, we established a connection between the clusters and the successrelated BMCs (Fig. 4). The first business model type identifies human resources and data content as the most important parts of value creation. The value proposition is based on these resources and describes comparison and categorization services with additional database and search services. On the value delivery side, revenue models considering supplementary services and one-time-charges are related to success. The second type significantly benefits from know-how resources and know-how transfer based on market expansion. Cloud services in this type are produced based on proprietary hardware resources, and the great width of the product portfolio allows economies of scale and cost. Additionally, a customer community reduces the efforts to provide individual support. The third type has a cloud business model based on vertical diversification, and succeeds in providing platform services with administration and integration assistance. The mix of private and hybrid cloud structures combined with transparent monitoring and usage-based payments is critical to success.

While the third type has by far the highest relative share of critical BMCs (71\% of all BMCs in cluster 3 are success-related), one third of the BMCs in the second type are success-related and the first type provides the least successrelated BMCs $(16 \%$ of all BMCs in cluster 1 are successrelated). We will therefore evaluate this situation further to obtain a better understanding and to formulate recommendations for action. 


\section{Expert Evaluation of the Analysis Results}

\subsection{Evaluation of the Success Factors in Cloud Business Models}

To evaluate our research results, we conducted expert interviews, as described in the research approach section. In the first part of the interview, the experts were asked to rank the identified components of a business model according to what they believed drives the success of a cloud business model. We built a ranking scale derived from the responses of all 12 experts and compared it to the literature concerning success factors, and also to the correlation analysis related to success. The components featured in the cloud literature results were ranked by the number of studies which had addressed this business model component, and the number of specific success factors. The components featured in the analysis of critical BMCs were ranked according to their relative share of the critical BMCs which correlated for each component. Whilst most of the components' ranks stayed relatively stable when comparing the literature and analysis results, the interviews revealed relevant differences (Fig. 5).

Firstly we consider those components that have increased their importance in the expert opinions. Business strategy was already highly ranked in literature and practice, and the experts considered it as the most important component. The experts stated that innovation and a clear strategy are especially important to differentiate a business model on the cloud market, and to build up a customer base. The importance of the distribution and customer relationship was not valued very highly in either the literature or the analysis results, but moved to second position within the interviews. A good customer relationship was cited as very important, especially with highly standardized cloud services. The target market was also assessed as a more important component by the experts, who argued that new and specified cloud business models have to find a concrete market. The importance of partner networks is not highly valued in the literature or the analysis results, but it stood out more in the expert interviews. Partner networks were mentioned as valuable ways to create end-to-end solutions and decrease the time-to-market. The cost view is seen as the least important component in literature but was more appreciated within the analysis and also in expert opinion. Nevertheless, the experts argued that a cost focus would impede new cloud providers from innovating and that it was a more valuable consideration for large providers and saturated markets. Components that have a decreased importance in the expert opinions are those of value proposition, revenue systems, as well as resources and activities to create value. The value proposition is mentioned as the most important component in literature and loses one rank position in the business model analysis and a further rank in the expert interviews in favor of other components. Nevertheless, cloud computing is mentioned as a highly disruptive concept that makes it possible that a huge variety of new services is made available to the cloud market. The revenue perspective was ranked within the upper half in the literature, but lost importance in the analysis and expert opinion. The experts argued that a valuable cloud service will have no problems finding a customer base that pays for it. Resources and activities were ranked highly in the literature and analysis results, but moved down to last place in the experts' views. The experts argued that resources are not important in the cloud market, because they already exist at the customers' workplace or can easily be purchased on a cloud basis.

\subsection{Evaluation of the Cloud Business Model Types}

The second part of the interview addressed the business model types revealed in the analysis. The experts were asked what recommendations for action they would give to providers who can to certain extent identify with one of these types and want to increase their success.

The newcomer cloud providers (first type) are faced with a crowded market and need to define and understand their market entry strategy and their target market very well (e.g., to find niche markets with wealthy customers). They should use their advantages as a small and flexible provider and develop agile, lean and specialized cloud services, and not focus on providing commodity IT. To take a look at the further developed US market was also thought of as beneficial. A partner network between providers is seen as valuable for scalability, risk reduction,
Fig. 5 Comparison of the previous research results with the expert opinions

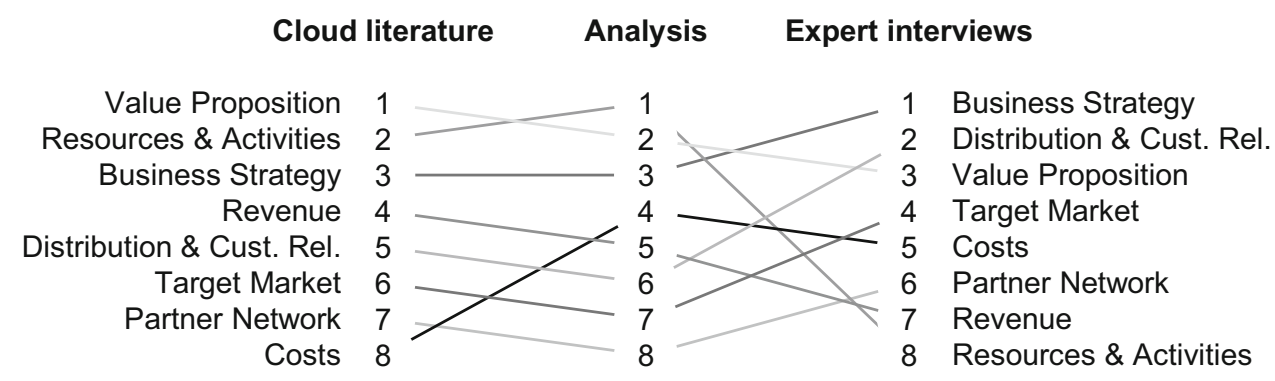


capital reduction, economies of scale, know-how increase, and for achieving a faster time to market. This serves as a booster until the company has established itself and gained enough experience and credentials. In the long-term, partner dependencies should be reduced to minimize risks and weaknesses, because, as one expert put it, "it is still a battle". The financial components of costs and revenue streams play a secondary role compared to achieving the right core concept for the right market.

The standardized mass-ware providers (second type) have high economies of scale and a good understanding of their technology. Due to standardized services, a low trust level, and less direct contact with customers, it is crucial for success to focus on a sound customer relationship, effective branding, and a marketing strategy. Customer analyses help to specify the customer's demands and to "imagine what the customers want before they know they need it". Furthermore, as the provided services are probably too complex for the average customer, providers need to increase their levels of transparency and find an appropriate pricing model to generate revenue streams from their products and services. Low service entry barriers such as free trials and premium customer services can also serve to increase profits. Channels, partnerships and target markets are either already established or easier to create in order to sell the value proposition. Therefore, these components are not highly critical to success.

The specialized cloud providers (third type) "understand what, why and where they are doing what they are doing". An innovative and high quality core value, the right security strategy, and a high degree of customer orientation are seen to result in high levels of trust and customer loyalty. A partner network can be established to create endto-end solutions, and providers must ensure that the business model cannot be easily imitated. The offer of options in the combination of on- and off-premises services in hybrid cloud solutions and a smooth-running transformation process are still unique selling propositions, but in the future, legacy systems will become obsolete and each service will be standardized and flexible. To compensate for the lack of scalability in personal customer care, these providers need to use the cloud concept as a disruptive technology and one which drives for continuous innovations that create customer needs.

\section{Conclusion}

The purpose of our research was to determine the successrelated characteristics of a cloud business model, in order to assess common cloud provider types (research question 1). For this reason, we initially compared the literature regarding the success factors of generic and cloud business models, and revealed a focus on value proposition, resources and activities, and also the cloud strategy. We complemented these literature results with a business model analysis of 45 cloud firms, using a framework comprising 105 business model characteristics (BMCs). A correlation analysis revealed a set of 42 success-related critical BMCs that confirmed the importance of the same business model components that were highlighted in the literature. Through cluster analysis, we revealed three common patterns of BMC combinations that describe business model meta types: (1) Newcomers with aggregation services possibly cooperating with partner revenue models, (2) experienced players with standardized public cloud services and customer care for the mass market, and (3) specified providers at a high trust level with hybrid branch solutions and integration support. The matching of the results from the correlation and cluster analysis supports the assessment of these different types and also the initial approaches which form recommendations for success. The third business model type was most visibly linked to success, while the first type was interpreted as least successful and as one which has difficulties competing in the cloud market.

In our evaluation interviews with 12 experts, we reviewed the success factors highlighted in literature and our analysis, and discussed further advice that may serve to increase the success of the featured business model types (research question 2). The aggregated expert knowledge offered recommendations that can be extended to shape the business models of cloud providers who regard themselves to match one of these three meta types. Cloud providers can use these recommendations as guidelines to optimize their business models, and so increase their potential for success.

Regarding our research, we accept some limitations. For the analysis of the cloud business models, we utilized the information given on company websites and news feeds. Such information is by nature subjective, and although we evaluated it using the principle of double control, we cannot prove the reliability of the information stated by the individual firms. Furthermore, as the cloud market is changing rapidly (e.g., SAP bought Concur in December 2014), our results may not be current. However, research on key indicators for business model success seems to be a neglected area. Especially in young markets where companies do not tend to classify their financial information, more measures should be employed that may point to the potential success of a business model. Lastly, as a point of methodology, the ranking of the interview results has limited empirical value due to the small sample of 12 interviews. However, the interview subjects were all considered expert in their field, and given their general agreement on the issues discussed there is no immediate 
reason to doubt that the results may be taken as reasonably representative of this market sector.

For the purposes of future research, we propose to break down our meta-approach and conduct selective analyses of firms with the same size, age or cloud level focus to produce results that are more detailed. Moreover, we suggest deepening the research conducted on deriving reliable indicators for the success of a business model.

\section{References}

Al-Debei MM, Avison D (2010) Developing a unified framework of the business model concept. Eur J Inf Syst (EJIS) 19(3):359-376

Anderberg MR (1973) Cluster analysis for applications. Academic Press, New York

Bacher J, Pöge A, Wenzig K (2010) Clusteranalyse: Anwendungsorientierte Einführung in Klassifikationsverfahren, 3rd edn. Oldenbourg, München

Baxter J, Eyles J (1997) Evaluating qualitative research in social geography: establishing 'rigour' in interview analysis. Trans Inst Br Geogr 22:505-525

Bettis RA, Hitt MA (1995) The new competitive landscape. Strateg Manag J (SMJ) 16(S1):7-19

Blashfield RK (1976) Mixture model tests of cluster analysis: accuracy of four agglomerative hierarchical methods. J Psychol Bull 83(3):377-388

Burkhart T, Krumeich J, Werth D, Loos P (2011) Analyzing the business model concept - a comprehensive classification of literature. In: Proceedings of the International Conference on Information Systems (ICIS) 32

Cohen SS, Zysman J, DeLong BJ (2000) Tools for thought: what is new and important about the "e-conomy"? Berkeley Roundtable on the International Economy. University of California, Berkeley

Creswell JW, Clark VL (2007) Designing and conducting mixed methods research. Sage, Thousand Oaks, CA

de Brentani U (1991) Success factors in developing new business services. Eur J Mark 25(2):33-59

Eccles RG (1991) The performance measurement manifesto. Harv Bus Rev 69(1):131-137

Ernst CH, Rothlauf F (2012) Potenzielle Erfolgsfaktoren von SaaSUnternehmen. In: Proceedings of the Multikonferenz Wirtschaftsinformatik (MKWI)

Faust D (1982) A needed component in prescriptions for science: empirical knowledge of human cognitive limitations. Sci Commun 3(4):555-570

Franz H, Kopp R (2004) Betriebliche Experteninterviews. Sozialwissenschaften und Berufspraxis 27(1):51-61

Gartner (2013) Hype cycle for emerging technologies 2013: Gartner's 2013 hype cycle for emerging technologies maps out evolving relationship between humans and machines. http://www.gartner. com/newsroom/id/2575515

Gaskell G (2000) Individual and group interviewing. In: Bauer MW, Gaskell G (eds) Qualitative researching: a practical handbook. Sage, London, pp 38-56

Gläser J, Laudel G (2010) Experteninterviews und qualitative Inhaltsanalyse, 4th edn. Springer Fachmedien, Wiesbaden

Gordon RJ (2000) Does the "New Economy" measure up to the great inventions of the past? National Bureau of Economic Research. Working Paper 7833
Grupp H, Schubert T (2010) Review and new evidence on composite innovation indicators for evaluating national performance. Res Policy 39(1):67-78

Hayes B (2008) Cloud computing. Commun ACM 51(7):9-11

Hopf C (2004) Qualitative interviews: an overview. In: Flick U, von Kardoff E, Steinke I (eds) A companion to qualitative research. Sage, London, pp 203-208

Horsti A, Tolonen J, Brannback M (2004) Electronic business models: five cases from five industries. In: Proceedings of the European conference on information systems (ECIS)

Hsieh H, Shannon SE (2005) Three approaches to qualitative content analysis. J Qual Health Res 15(9):1277-1288

Ittner CD, Larcker DF, Meyer MW (2003) Subjectivity and the weighting of performance measures: Evidence from a balanced scorecard. Account Rev 78(3):725-758

Kirsch LJ (2004) Deploying common systems globally: the dynamics of control. Int J Inf Syst Res 15(4):374-395

Labes S, Erek K, Zarnekow R (2013a) Common patterns of cloud business models. In: Proceedings of the Americas conference on information systems (AMCIS) 19

Labes S, Erek K, Zarnekow R (2013b) Literaturübersicht von Geschäftsmodellen in der Cloud. In: Proceedings of the international conference on Wirtschaftsinformatik (WI) 11

Labes S, Hanner N, Zarnekow R (2015) Success factors of cloud business models. In: Proceedings of the European conference on information systems (ECIS) 23

Lambert SC, Davidson RA (2013) Applications of the business model in studies of enterprise success, innovation and classification: an analysis of empirical research from 1996 to 2010. Eur Manag J (EMJ) 31:668-681

Lee AH, Chen W, Chang C (2008) A fuzzy AHP and BSC approach for evaluating performance of IT department in the manufacturing industry in Taiwan. Expert Syst Appl 34(1):96-107

Leidecker JK, Bruno AV (1984) Identifying and using critical success factors. Int J Long Range Plan (LRP) 17(1):23-32

Liebhold R, Trinczek R (2009) Experteninterviews. VS Verlag für Sozialwissenschaften, Wiesbaden

Mayring P (2004) Qualitative content analysis. In: Flick U, von Kardoff E, Steinke I (eds) A companion to qualitative research. Sage, London, pp 266-269

Mell P, Grance T (2011) The NIST definition of cloud computing. National Institute of Standards and Technology (NIST) Computer Security. doi:10.6028/NIST.SP.800-145

Miles MB, Huberman AM (1994) Qalitative data analysis. Sage, London

Myers MD (1997) Qualitative research in information systems. MIS Q 21(June):241-242

Osterwalder A (2004) The business model ontology: a proposition in a design science approach. Thesis. Université de Lausanne

Osterwalder A, Pigneur Y, Clark T (2010) Business model generation: a handbook for visionaries, game changers, and challengers. Wiley, Hoboken

Peters TJ, Waterman RH (1982) In search of excellence: lessons from America's best-run companies, 2nd edn. Profile, London

Punj G, Stewart DW (1983) Cluster analysis in marketing research: review and suggestions for application. J Mark Res 20(May):134-148

Rockart JF (1979) Chief executives define their own data needs. Harv Bus Rev 57(2):81-93

Rockart JF (1982) The changing role of the inf syst executive: a critical success factors perspective. Sloan Manag Rev 23(1):3-13

Schilling J (2006) On the pragmatics of qualitative assessment: designing the process for content analysis. Eur J Psychol Assess 22(1):28-37 
Schoeffler S, Buzzell RD, Heany DF (1974) Impact of strategic planning on profit performance. Harvard University, Boston, MA, Graduate School of Business Administration, pp 137-145

Shafer SM, Smith HJ, Linder JC (2005) The power of business models. Bus Horizons 48:199-207

Staehler P (2002) Business models as an unit of analysis for strategizing. International Workshop on Business Models. http:// www.hec.unil.ch/aosterwa/Documents/workshop/Draft_Staeh ler.pdf. Accessed 28 Aug 2016

Thomas DR (2006) A general inductive approach for analyzing qualitative evaluation data. Am J Eval 27(2):237-246

Vaughan L (2004) Exploring website features for business information. J Scientometr 61(3):467-477

Vaughan L, Yang R (2012) Web data as academic and business quality estimates: a comparison of three data sources. J Am Soc Inf Sci Technol (ASIS\&T) 63(10):1960-1972

Veit D, Clemons E, Benlian A, Buxmann P, Hess T, Kundisch D, Leimeister JM, Loos P, Spann M (2014) Business models. Bus Inf Syst Eng 6(1):45-53

Venkatesh V, Brown SA, Bala H (2013) Bridging the qualitativequantitative divide: guidelines for conducting mixed methods research in information systems. MIS Q 37(1):21-54
Walther S, Plank A, Eymann T, Singh N, Phadke G (2012) Success factors and value propositions of software as a service providers - a literature review and classification. In: Proceedings of the Americas conference on Inf Syst (AMCIS)

Wang F, Vaughan L (2014) Firm web visibility and its business value. J Internet Res (INTR) 24(3):292-312

Weinhardt C, Anandasivam A, Blau B, Borissov N, Meinl T, Michalk W, Stößer J (2009) Cloud computing - a classification, business models, and research directions. Bus Inf Syst Eng 1(5):391-399. doi:10.1007/s12599-009-0071-2

Wirtz BW (2010) Electronic business, 3rd edn. Gabler, Wiesbaden

Patton MQ (2005) Qualitative research. Wiley, New York

Zerdick A, Picot A, Schrape K, Artope A, Goldhammer K, Heger DK, Lange UT, Vierkant E, Lopez-Escobar E, Silverstone R (2001) Die Internet-Ökonomie: Strategien für die digitale Wirtschaft. Europ Commun Council Rep, 3rd edn. Springer, Berlin, Heidelberg

Zolnowski A, Boehmann T (2011) Business modeling for services: current state and research perspectives. In: Proceedings of the Americas conference on information systems (AMCIS) 17

Zott C, Amit R, Massa L (2011) The business model: recent developments and future research. J Manag (JoM) 37(4):1019-1042 